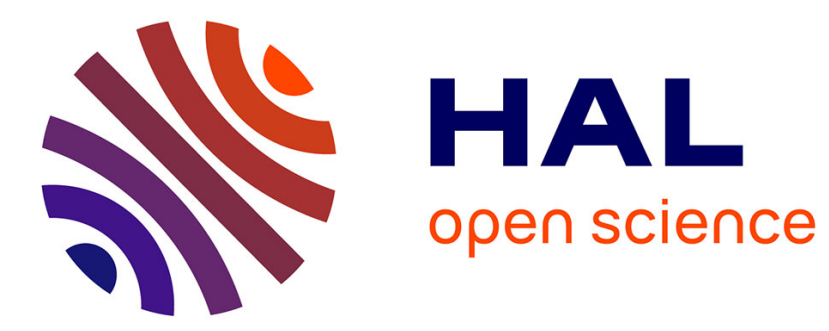

\title{
Olfactory, gustatory and tactile perception in Beja (North-Cushitic).
}

Martine Vanhove, Mohamed-Tahir Hamid

\section{To cite this version:}

Martine Vanhove, Mohamed-Tahir Hamid. Olfactory, gustatory and tactile perception in Beja (NorthCushitic).. Linguistics of Olfaction, Łukasz Jędrzejowski, Malika Reetz \& Staniewski Staniewski (eds.). Amsterdam, Philadelphia: Benjamins., John Benjamins, pp.175-198, 2021. halshs-02447576

\section{HAL Id: halshs-02447576 \\ https://shs.hal.science/halshs-02447576}

Submitted on 21 Jan 2020

HAL is a multi-disciplinary open access archive for the deposit and dissemination of scientific research documents, whether they are published or not. The documents may come from teaching and research institutions in France or abroad, or from public or private research centers.
L'archive ouverte pluridisciplinaire HAL, est destinée au dépôt et à la diffusion de documents scientifiques de niveau recherche, publiés ou non, émanant des établissements d'enseignement et de recherche français ou étrangers, des laboratoires publics ou privés. 


\section{Olfactory, gustatory and tactile perception in Beja (North-Cushitic)}

Martine Vanhove

Llacan (UMR 8135, CNRS, INALCO, Université Sorbonne Paris-Cité)

Mohamed-Tahir Hamid Ahmed

Sudan University of Science and Technology (SUST, Khartoum, Sudan) and Omdurman Ahlia University (OAU, Omdurman, Sudan)

\section{Abstract}

This chapter studies the perception words associated with the so-called "lower senses" (olfaction, gustatory and tactile perceptions) in Beja, a Cushitic language spoken mainly in Sudan, from three different perspectives. The first one concerns the organization of the related lexicon from the point of view of word categories, and their semantic aspects along a positive / negative and more intense / less intense continuum.

Numerically, it shows a prevalence of the verb category over nouns and adjectives, and a more varied lexicon for smell, than for taste and touch. The second one provides a study of the syntactic constructions of perception words. It shows a prevalence of source-oriented constructions except in the tactile domain. The third one deals with the metaphorical extensions of the 
perception words for each sensory modality. The last section discusses the Beja findings in a broader comparative and typological perspective.

\section{Keywords}

Perception, semantics, syntax, metaphor, Beja

\section{Introduction}

Beja is the sole member of the North-Cushitic branch of the Afroasiatic phylum. It is mainly spoken in Eastern Sudan. The 1993 census, the last to contain a question about language, gives a total number of approx.

$1,100,000$ speakers. There are probably more now. Dialectal differences are not numerous, mostly lexical and phonological, and they do not jeopardize inter-comprehension.

The data used for this chapter are taken from various sources: texts of the central and southern varieties recorded in Sudan between 2000 and 2011 by the first author, dictionaries (Reinisch 1895, northern variety; Roper 1928, central variety), and elicitation with the second author who is an anthropologist and a native speaker of the southern variety. It was performed during his stay in Paris in 2016, but there was time only for basic 
elicitation, and none to use the stimuli that deal with the traditional five senses, in particular the olfactory kit designed at the MPI (Majid et al. 2007). Consequently, it was not possible to answer the research question about the terminological and constructional consistency within the Beja community for describing sensory experiences.

After a brief outline of the main characteristics of the Beja morphosyntax necessary for a better understanding of the examples (Section 2), this chapter investigates the three lower senses of olfaction (Section 3), taste (Section 4) and touch (Section 5), because there is some overlap between the three modalities. For all senses the organization of the lexicon is discussed, then their syntactic constructions, and finally their metaphorical extensions. The conclusion (Section 6) discusses the Beja findings in a broader comparative and typological perspective.

The Beja vocabulary associated with the three lower senses is not particularly elaborated although not very poor: All in all, 56 terms were recorded, but this figure goes down to eighteen when one considers the number of different roots, one root being often used for the four word categories involved: verb, noun, adjective and manner converb. We are far from the richness of certain Bantu languages such as Lumongo (Hulstaert 1957) or Setswana (Creissels \& Chebanne 2000). Moreover, Beja has neither phonemic specificity nor morphological dedicated category for the expression of the lower senses, such as ideophones (which do not constitute a word class in Beja), categorical hybrids or invariant nouns, as is often the 
case in the languages of Africa for which we have available studies, e.g. in Kapsiki (van Beek 1992), Tarok (Blench \& Longtau 1995), Luwo (Storch 2004), Kambaata (Treis 2010), or Siwu (Dingemanse 2011; Dingemanse \& Majid 2012).

\section{Some basic aspects of Beja morphosyntax}

Beja has a rich and complex morphology, both verbal and nominal. Part of the lexicon is organized, as in Arabic, with a system of roots, stems and patterns based on a combination of ablaut, affixes and reduplications that form nouns, adjectives, plurals, verb inflection and derivation. The morphology is also concatenative, partly with portmanteau morphemes.

Beja is a marked nominative language, with three lexical cases, nominative, accusative and genitive. They are marked on clitic determiners for the first two (overtly expressed only if the syllabic structure of the noun permits), and on the dependent noun for the last one. Pronouns have in addition dative and ablative/locative ${ }^{1}$ cases, but dative, ablative and locative are expressed by (clitic) postpositions for nouns.

\footnotetext{
${ }^{1}$ For sake of brevity, this set of pronouns is only glossed ABL (ablative) in the glossing lines.
} 
There are two genders, masculine and feminine, two numbers, singular and plural, and two types of articles. The definite ones are proclitic, the indefinite are enclitic. They are overtly marked for gender, number and case, again if the syllabic structure of the noun permits. Nouns may thus be used in the bare form without any overtly expressed determiners. ${ }^{2}$

Verbs have finite and nonfinite forms. Verb paradigms are marked for aspect, mood, person, number and gender. Finite forms have three aspects: imperfective, perfective and aorist. Complex predicates are used to express other aspects, tenses and modalities, and for light verb constructions. They are formed with auxiliaries or the copula. Beja has two morphologically based verb classes: A small majority is conjugated with prefixes (and suffixes in the plural); it is historically the oldest verb class. The other verb class is conjugated with suffixes only. There are six to seven derived verb stems (depending on the verb class): intensive, pluractional, middle, passive (for the prefix class), reciprocal-sociative, causative, double causative. Combinations of two, sometimes three, derived forms are possible. Nonfinite forms amount to four converbs: general, sequential, simultaneity and manner. The manner converb can also be used as an adjective modifier.

\footnotetext{
${ }^{2}$ For sake of clarity, the syntactic function of bare nouns in the examples is marked in the glossing line in between brackets: [SBJ] for the subject function and $[\mathrm{OBJ}]$ for the object function.
} 
Syntactically, Beja is largely head final. The canonical word order is $(\mathrm{X})(\mathrm{S})(\mathrm{O}) \mathrm{V}$ and the clause order is dependent - main clause. But word and clause order may vary for pragmatic reasons.

\section{Olfaction}

\subsection{Organization of the lexicon}

The vocabulary of olfaction is the most elaborated among the lower senses: 27 items, representing almost half of the total vocabulary of the lower senses (48.20\%), and exactly half of its number of roots (9/18).

Table 1 presents the olfactory lexicon organized on the vertical axis on a scale of intensity, and on the horizontal axis by hedonic polarity, positive $v s$ negative (attractive/pleasant $v s$ repellent/unpleasant smells), and word category.

Table 1. The olfactory lexicon of Beja 


\begin{tabular}{|c|c|c|c|c|c|c|}
\hline & \multicolumn{3}{|l|}{ Positive } & \multicolumn{3}{|l|}{ Negative } \\
\hline & verb & noun & adjective & verb & noun & CVB.MNR \\
\hline +intense & $\begin{array}{l}\text { fik } k^{w} a: n \\
\text { 'emit a } \\
\text { pleasant } \\
\text { odor' }\end{array}$ & $\begin{array}{l}\int a k^{w} i: n \\
\text { 'fragrance' }\end{array}$ & $\begin{array}{l}\text { fik } k^{w} a: n \text {-lo:j } \\
\text { 'perfumed- } \\
\text { AUG' } \\
\text { fikwa:n } \\
\text { 'perfumed' }\end{array}$ & $\begin{array}{l}\text { dimi 'stink' } \\
k^{w i m h a} \\
\text { 'smell bad' } \\
\text { ?abis } \\
\text { 'exhale a } \\
\text { fermented } \\
\text { smell' } \\
\text { harr?a:k } \\
\text { 'smell of } \\
\text { burning' }\end{array}$ & $\begin{array}{l}\text { dimj-a:j=t } \\
\text { 'stink- } \\
\text { N.AC=F' } \\
k^{\text {wimha }} \\
\text { 'bad smell' } \\
\text { ?abis } \\
\text { 'fermented } \\
\text { smell' }\end{array}$ & $\begin{array}{l}\text { dimj-a-l } \\
\text { 'stink- } \\
\text { CVB.MNR- } \\
\text { AUG' } \\
\text { dimj-a } \\
\text { 'stink- } \\
\text { CVB.MNR' } \\
\\
k^{w i m h a-a} \\
\text { 'smell bad- } \\
\text { CVB.MNR' } \\
\text { Pabis-a } \\
\text { 'exhale a } \\
\text { fermented } \\
\text { smell- } \\
\text { CVB.MNR' }\end{array}$ \\
\hline neuter & $\begin{array}{l}\text { bara:m } \\
\text { 'smell of' } \\
\text { f?a 'smell' } \\
\text { d?a:f } \\
\text { 'exhale a } \\
\text { light smell' } \\
\text { fi:k 'sniff' } \\
\text { fi:k-am } \\
\text { 'sniff-MID' } \\
\text { fa fi:k-am } \\
\text { 'PLAC- } \\
\text { sniff-MID' } \\
\text { fi:k-am-s } \\
\text { 'sniff-MID- } \\
\text { CAUS' }\end{array}$ & $\begin{array}{l}\text { bara:m } \\
\text { 'odor' } \\
\text { f?a-ti } \\
\text { 'smell- } \\
\text { N.AC' } \\
\text { d?a:f 'light } \\
\text { smell' }\end{array}$ & & $\begin{array}{l}\text { bara:m } \\
\text { 'smell of' } \\
\\
\text { dia:f } \\
\text { 'exhale a } \\
\text { light smell' } \\
\text { (fi:k 'sniff') } \\
\text { (fi:k-am } \\
\text { 'sniff- } \\
\text { MID') }\end{array}$ & $\begin{array}{l}\text { dimja } \\
\text { bara:m } \\
\text { 'stinking } \\
\text { odor' }\end{array}$ & \\
\hline -intense & $\begin{array}{l}\text { bara:m t?a } \\
\text { 'exhale a } \\
\text { light smell' }\end{array}$ & $\begin{array}{l}\text { t?a-na:j } \\
\text { 'light } \\
\text { smell' }\end{array}$ & & $\begin{array}{l}\text { bara:m t?a } \\
\text { 'exhale a } \\
\text { light smell' }\end{array}$ & $\begin{array}{l}\text { t?a-na:j } \\
\text { 'light } \\
\text { smell' }\end{array}$ & \\
\hline
\end{tabular}

One root, Pra: $^{\text {'to exhale a light smell', is an Arabic loan. }}{ }^{3}$

${ }^{3}$ The Sudanese Arabic noun daSa:f, a poetic term, means precisely 'smell of a mixture of rain, dust and fodder grass; smell of rainy clouds beginning to 
The verb category is the largest (18 items: 9 roots and 1 compound), followed by nouns (12 items: 4 roots and 1 compound), while the adjective and manner converb (used as attributive adjective) categories are the poorest (6 items: 4 roots).

There are more roots to express intense negative odors: four (dimi 'stink',

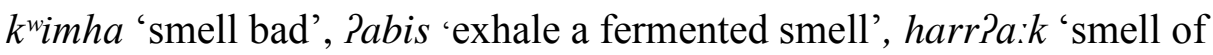
burning'), while there is only one ( $\int i k^{w} a: n$ 'emit a pleasant odor, smell nice, perfume o.s.') to express intense positive odors. This difference reflects a general tendency across languages (Boisson 1997: 9).

Within the neuter scale of intensity, words denoting pleasant smells predominate over unpleasant ones: One root ( $f$ ? $a^{\text {' }}$ smell, sniff'), and two derived verb forms ( $\int a \sim f i: k$-am 'to smell, scent, inhale', and $\int i: k$-am-s 'to make sniff') are exclusively dedicated to pleasant odors. Two verbs of the same $\operatorname{root}(f i: k$ 'to snuffle, sniff' and $f i: k$-am 'to sniff') can only marginally be associated with unpleasant smells, ${ }^{4}$ in the sense that these activity verbs are used when the speaker is trying to figure out if a smell is pleasant as expected, even though an unpleasant one could be detected. Two verbs, bara:m 'to smell of', and $d ? a: f$ 'to exhale a light smell', can be used for both hedonic polarities, but the noun form bara:m 'smell, odor' is usually

shape; nice smell; cold wind that blows after a rain fall' ('Awn Al-Sharif Qasim 2002: 333).

${ }^{4}$ This is why they are in parentheses in Table 1. 
qualified by the repellent manner converb, dimj- $a$ 'stinky', when referring to a repulsive odor.

The lower part of the intensity scale shows a complex construction involving the activity verb $t ? a$ 'to hit' and the neuter noun bara:m 'smell, odor': bara:m t?a 'to exhale a light smell'. The corresponding noun is a compound which nominalizes the verb $t ? a$ 'to hit' by means of the dummy noun $n a(: j)$ 'thing': t?a-na:j 'light smell'. Although not strictly basic terms since they are bi-lexemic, the constructions are felt as belonging to the basic set of olfactory verbs by the second author. These complex forms are reminiscent of the 'hit' origin of certain (intense and unpleasant) smell terms in some Indo-European languages (Buck 1949 [1988]: 1023-1024; Boisson 1997: 7). The differences are that in Beja the constructions are evaluated as non-intense, and can be used for both attractive and repulsive smells.

Two experience verbs in the negative polarity are related to specific kinds of smell: ?abis 'to exhale a fermented smell', perceived as intense, and harr?a:k' to smell of burning, ${ }^{5}$ which is only perceived as slightly unpleasant although intense.

\footnotetext{
${ }^{5}$ It is unsure if this verb is an Arabic loan from haraqa 'burn'. If a change from $q / g$ in Arabic to $k$ in Beja is attested, the addition of a laryngeal stop ? is unattested in borrowings from Arabic.
} 
Morphologically, the adjective and the manner converb of the upper part of the intensity scale display the augmentative suffixes $-l o: j$ and $-l$. It was not possible to elicit these suffixes with the other olfactory adjectives and manner converbs. Below are two examples taken from texts.

\author{
(1) misu:s dimi-a-l \\ dielN.AC stink-CVB.MNR-AUG \\ ti-katij=e:b o:=do:r \\ DEF.SG.M.ACC=time 2SG.M-becomelIPFV=REL.M \\ 'When you'll be a very stinky corpse...' \\ (BEJ_MV_NARR_32_King_62-63) ${ }^{6}$
}

\footnotetext{
${ }^{6}$ Examples followed by a reference in parentheses are taken from two online corpora collected by the first author. They were part of two ANR (Agence National de la Recherche) projects led by Amina Mettouchi, CorpAfroAs and CorTypo. They are freely available at http://dx.doi.org/10.1075/scl.68.website, and http://cortypo.huma-num.fr/. Texts from 01 to 18 belong to the CorpAfroAs corpus (Vanhove 2014), and texts from 19 to 58 to the CorTypo corpus (Vanhove 2018).
} 
(2) mPari wi=i-ti:kwa

food REL.M=3SG.M-cook\AOR

$b i=n-k a: n=e: t \quad \quad f i k^{w} a: n-l o: j=t$

NEG.OPT=1PL-know $\backslash$ MID=REL.F $\quad$ perfumed-AUG=INDF.F

'A meal, that we don't know who cooked it, smelling very

nice...' (BEJ_MV_NARR_58_Ababda_193-208)

Within the verb derivational system, all verb forms are basic forms (i.e. underived), except three in the neuter lines. fi:k-am 'to sniff' is the middle derived form of $f i: k, f i: k$-am-s its middle and causative (see ex. 3 below), and fa fi:k-am 'to smell, scent, inhale' is the pluractional of the middle form. The fact that the latter is perceived as a neuter verb form in terms of intensity implies that its semantic value has nothing to do with intensity, one of the possible meanings of pluractionals, but only with plurality of events, be they repeated or successive actions, or distributive actions with several localizations or goals. ${ }^{7}$

${ }^{7}$ See Vanhove (2017) and Mattiola (2017) for pluractionality in Beja. 
(3) $\quad i=$ ginu: $f-i=d a$

DEF.M=nose-GEN=DIR

$d a:-s-i=t$

be_there-CAUS-AOR.3SG.M=COORD

fi:k-am-s-e:n o: $=$ do:r

sniff-MID-CAUS-IPFV.3PL DEF.SG.M.ACC=time

$i=g a \sim g a m-i=e: b$

REL.M=PLAC $\sim$ shout-AOR.3SG.M=REL.M

'They used to put it (the dry meat) under its nose and make it (the baby) smell it when it used to cry a lot.' (in order to calm the baby down) (BEJ_MV_NARR_33_Meat_11)

Semantically, there is one dialectal difference. The verb $f i: k$ is only known with the meaning 'to snuff; to chew tobacco' in the southern variety. This dialect uses instead the middle form $/ i$-am (known also in the other two varieties), which precisely means 'to sniff for a long time, taking a long breath, in order to determine the nature of the thing smelled' (e.g. a farmer in order to know if the sorghum is ripe or not, or if the milk, cream or ghee is good or not). The precise meaning of $f ? a$ is also 'to smell, sniff in order to determine the nature of the thing smelled', but the odor is necessarily

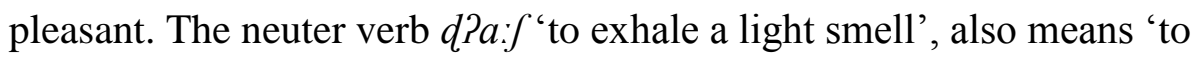
exhale an unexpected smell'. 
The Beja lexicon shows a semantic connection between olfaction and weather terminology. The generic and neuter noun bara:m 'smell, odor' also means 'wind', and another neuter noun $d$ Pa:f 'light smell' also means 'breeze'. Another noun for 'breeze' is the compound bara:m-t?a (lit. smell/odor/wind-hit) at the bottom of Table 1, which also shows the semantic link between weather terms and olfaction.

An adjective and a manner converb are used to qualify odor terms. The adjective comes from the temperature semantic field: ${ }^{8} l ? a$ 'cold', and can apply to both an attractive and a repellent smell: $l$ ?a bara:m-i=t fakwi:n [cold smell-GEN=F perfume] 'a perfume with a light (unpleasant or not) smell' (lit. of a cold smell). Temperature terms are also sporadically associated with olfaction in other languages of the world, with different shades of meaning: English and Serbian (Rasulić 2015: 288), Ukranian (Kryvenko 2015: 321), Finnish (Juvonen and Nikunlassi 2015: 525), and Indonesian (Siahaan 2015: 695). Olfaction is associated to a manner converb, Pakr- $a$ 'strong' denoting physical strength (which also applies to natural elements such as 'wind', 'storm'), an association not uncommon cross-linguistically, such as in French: ?akr-a bara:m-i=t fakwi:n [be strongCVB.MNR smell-GEN-F perfume] 'a perfume with a strong smell; an intoxicating perfume'.

${ }^{8}$ For a preliminary experiment concerning the association of olfaction and temperature terms in diverse languages, see Wnuk et al. (2017). 
On the other hand, the intense positive and negative adjectival and converb forms, $\int i k^{w} a: n$ 'emitting a pleasant odor; perfumed', and dimj-a 'stinky', are used to qualify the intensity neuter noun bara:m 'smell, odor' as attractive or repellent: fikwa:n bara:m 'a nice smell', dimj-a bara:m 'a stinky smell'.

Nouns of olfaction (masdars, i.e. action nouns) are derived from the corresponding verb forms. One example is in (4).

$$
\begin{aligned}
& \text { (4) } t=h o: j=t=a: k \\
& \text { DEF.F=belly=INDF.F=POSS.2PL.NOM now } \\
& \text { dimij- } a: j=t \quad \text { Pata }: b=t=u \\
& \text { stink-N.AC=INDF.F full=INDF.F=COP.3SG } \\
& \text { 'Your belly now is full of stinky things' } \\
& \text { (BEJ_MV_NARR_32_King_52-55) }
\end{aligned}
$$

Pabis 'to exhale a fermented smell' is commonly used in light verb constructions with the verb $d i$ 'say' instead of the ordinary verb paradigms, to express a particularly intense and unpleasant smell as in (5).

$$
\begin{aligned}
& \text { (5) Pabis di-ja:=t } \\
& \text { fermented_smell say-CVB.MNR=REL.F } \\
& \text { lam }=t=i \\
& \text { sauce }=\mathrm{INDF} . \mathrm{F}=\mathrm{COP} .3 \mathrm{SG} \\
& \text { 'It is a sauce whose smell is unpleasantly fermented' }
\end{aligned}
$$




\subsection{Syntactic constructions}

fikwa:n 'to emit a pleasant odor', bara:m 'to smell of', and d?a:f 'to exhale a light smell' are intransitive experience verbs and are all source-oriented. They are non-agentive and the subject is always the source of the odor. Below are examples with the neuter verb bara:m. The experiencer is either an ablative/locative pronoun (6-8), or not mentioned at all (9-10).

(6) $\quad$ u:=fa:r ho:si bara:m-ja

DEF.SG.M.NOM=flower ABL.1SG smell_of-PFV.3SG.M

'I smelled the flower.' (lit. the flower smelled from/inside me)

(7) $\quad$ Pakr-a=t fakwin ho:si

be_strong-CVB.MNR=INDF.F fragrance ABL.1SG

bara:m-tini

smell_of-IPFV.3SG.F

'I smell an intoxicating perfume' (lit. a strong perfume smells from/inside me)

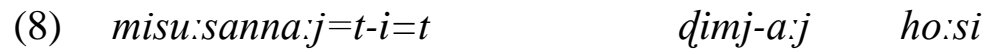

carrion=INDF.F-GEN=INDF.F stink-N.AC ABL.1SG

bara:m-ta

smell_of-PFV.3SG.F

'I smelled the stinking smell of the carrion' (lit. the stinking of the carrion smells from/inside me) 
(9) e:ga bara:m-i:ni

smoke smell_of-IPFV.3SG.M

'It smells of smoke' (lit. smoke smells)

(10) amba bara:m-i:n

shitlPL smell-AOR.3PL

'It was smelling of shit' (lit. shit smelled)

(BEJ_MV_NARR_18_Hunchback_416)

(11) and (12) are examples with the pleasant and unpleasant verbs of olfaction.
(11) $\int a k^{w} i: n=t$
d?a:S-tini
fragrance=INDF.F exhale_a_light_smell-IPFV.3SG.F
'A perfume exhales a light smell'
(12) $u:=b u: n$
harr?a:ki-ja
DEF.SG.M.NOM=coffee smell_of_burning-PFV.3SG.M
'The coffee smelt of burning'

On the contrary, the three activity verbs, $f ? a$ 'to smell, to sniff', $f i: k$ and fi:k-am 'to sniff' are not source-oriented. They are transitive, the subject (represented in the verb inflexion in ex. 12 and 13) is the experiencer, and the source of the odor is the direct object. 
(13) $o:=f a: r$

DEF.SG.M.ACC=flower smell-PFV.1SG

'I smelled the flower'

(14) $o:=$ fa:r

DEF.SG.M.ACC=flower sniff-MID-PFV.1SG f?-an

fi:k-am-an

'I sniffed the flower'

Odor expressions can be constructed with the transitive verb t?a 'to hit'. Contrary to the above transitive olfactory verbs, and like the intransitive verbs, the subject is the source of the odor. But unlike the intransitive verbs, the experiencer is expressed by an object pronoun, not an ablative/locative one. Such a construction is of course linked to the fact that $t ? a$ is transitive.

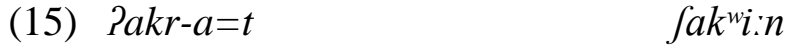 \\ be_strong-CVB.MNR=INDF.F fragrance \\ $t i-t ? a=h e: b$ \\ 3SG.F-hit $\mathrm{PFV}=\mathrm{OBJ} .1 \mathrm{SG}$ \\ 'I smelled an intoxicating perfume' (lit. a strong perfume hit me)
}

\title{
3.3. Metaphors
}

Metaphors based on olfaction are not numerous. It is actually the sensory modality which produces the lowest number of metaphors. The three attested metaphors are linked to the semantic domains of feelings and 
emotions. They are based on the intensity neuter verbs, the active $f$ ? $a$ 'to smell, to sniff', and the source-oriented bara:m 'to smell of'.

$f ? a$ can be used with the meaning 'to kiss' in between lovers, when the verb is preceded by the ablative/locative $3^{\text {rd }}$ person pronoun: ho:j f?a: 'to kiss' (lit. to smell from it); the subject is the agent.
(16)
ahmad lajla: $=b \quad$ ho:j
Ahmad Layla=INDF.M.ACC ABL.3
fri-ja
sniff-PFV.3SG.M
'Ahmad kissed Layla' (lit. A. sniffed from/inside L.)

The colexification of 'smell' and 'kiss' is widespread in the languages of Southeast Asia (see Shapper, this volume); it seems to be only sporadically attested in the languages of Africa. A search in the RefLex database (Segerer \& Flavier 2011-2018), which contains lexicons of 782 African languages, provided only five other languages of the Niger-Congo phylum with this colexification: Dii (Adamawa), Bambara and Soninke (Mande), Wolof and Fula (Atlantic). ${ }^{9}$

bara:m 'to smell of' is used to express yearning or anticipation of pleasant events, the latter being close to 'sense something intuitively' as described by

\footnotetext{
${ }^{9}$ There are more examples of African languages (15) which colexify 'kiss' with 'taste' or 'suck'.
} 
Ibarretxe-Antuñano (1999) for English, Spanish and Basque. Like in the concrete sense of the sensory modality, the syntactic construction makes the source of the emotion the subject of the verb and the ablative/locative pronoun refers to the experiencer.
$w=h a: \int$
ho:j bara:m-ja
DEF.M.NOM=country
ABL.3 smell_of-PFV.3SG.M

'He was homesick' (lit. the country smelled from/inside him)

(18)

ramada:n ho:si bara:m-ja

Ramadan ABL.1SG smell_of-PFV.3SG.M

'I felt Ramadan coming' (lit. Ramadan smelled from/inside me)

\section{Taste}

\subsection{Organization of the lexicon}

In terms of the number of lexical items, taste is the second sensory modality. There are five gustatory roots which produce sixteen items, representing $28.5 \%$ of the total lexicon of the lower senses. These lexical items are distributed across word categories as follows: seven verbs for four roots, six nouns for four roots, four adjectives for four roots and one manner converb for one root. Three roots (marked with \# in Table 2) are borrowings from 
Arabic. The lexicon is listed in Table 2 below by word category on the horizontal axis and hedonic polarity on the vertical axis.

Table 2. The gustatory lexicon of Beja

\begin{tabular}{|c|c|c|c|c|}
\hline & Verb & Noun & Adjective & Manner converb \\
\hline Positive & $\begin{array}{l}\text { nifir 'be sweet' } \\
\text { si-nafir } \\
\text { 'sweeten' } \\
\text { \#hamir 'be } \\
\text { sour' } \\
\text { \#s-hamir 'make } \\
\text { sour' }\end{array}$ & $\begin{array}{l}\text { nafru:r } \\
\text { 'sweetness' }\end{array}$ & nafir 'sweet' & \#hamr-a 'sour' \\
\hline Neuter & $\begin{array}{l}\text { \#d?am 'taste of' } \\
\text { \#d?am-s 'taste' }\end{array}$ & $\begin{array}{l}\text { \#dPam 'taste'/ } \\
\text { \#ta:mi } \\
\text { 'sweetness' } \\
\text { \#d?am-si-ti } \\
\text { 'taste' }\end{array}$ & \#ta:mi 'sweet' & \\
\hline Negative & $\begin{array}{l}\text { \#hami 'be } \\
\text { bitter' }\end{array}$ & $\begin{array}{l}\text { \#hami-ja:j } \\
\text { 'bitterness' } \\
\text { sira:j 'very bad } \\
\text { taste' }\end{array}$ & $\begin{array}{l}\text { \#hami 'bitter' } \\
\text { sira:j } \\
\text { 'disgusting' }\end{array}$ & \\
\hline
\end{tabular}

The taste experience verb diam 'to taste of' is related to the Arabic root TSM 'taste'. It can be made active via the causative derivation: $d$ Pam-s 'to taste, make taste', which is a polite way to invite people to eat, when used in the imperative paradigm: $d$ ?am-s- $a$ 'please eat!' (lit. taste!), instead of the straightforward order tam- $a$ 'eat!'. ${ }^{10}$ Its masdar is $d$ Pam-si-ti '(act of) tasting' and dPam 'taste' is the generic noun for the sensory modality. There is dialectal variation for this Arabic borrowing. Roper (1928), who described the central variety, does not provide the underived verb form (which is used today in this dialect), and the root is even absent from

${ }^{10}$ diam has no imperative. 
Reinisch (1895) who instead provides the form tāmi, a noun and an adjective, 'sü $\beta$; süßigkeit' ('sweet; sweetness'), placed under the main heading tam 'to eat', which Reinisch relates to Arabic TSM (as dPam), and cognate forms in various Semitic languages (including Ethio-Semitic Tigre and Gə’əz). Obviously, there are several layers of borrowings that took place in Beja, which gave different phonetic outputs and different shades of meaning.

Beja distinguishes four physiological evaluative tastes.

hamir 'to be sour', its causative s-hamir, and the manner converb hamr-a 'sour' come from the Arabic root $X M R$, which among other things means 'ferment; yeast'. 'Yeast' is the meaning of the Beja derived noun hami:r, not 'sourness', hence its absence form Table 2. hami 'bitter', hami 'to be bitter', hami-ja:j 'bitterness' (lit. to be bitter + masdar suffix -ja:j) are related by Reinisch (1895) to the Arabic root HMD of ћa:mid 'sour', implying that the final consonant was lost in Beja. While Reinisch translates both hamir and hami by 'sour' and 'bitter', the second author of this chapter makes a clear distinction between hamir 'to be sour', a pleasant taste, and hami 'to be bitter', an unpleasant one, which also conflates with the meaning 'to be too salty' applied to food and water alike. Whether this distinction is also made by other Beja speakers and varieties is open to further investigation. Both Roper's and Reinisch's dictionaries only mention the meaning 'salty, brackish' for water: $w=$ hami bhar 'the sea' (lit. the 
salted river), $t=$ hami jam 'the well of bitter water'. ${ }^{11}$ When talking about camel or cow milk, which traditionally constitute, with sorghum gruel, the basic diet of the Beja people, hamir typically applies to fermented milk with a good taste, while hami applies to a bad milk that has turned bitter. The third evaluative taste is sira:j, a noun and an adjective, which indicates an extreme negative degree of bitterness, a very bad taste, in particular for too salty food, again conflating bitterness and saltiness. The last gustatory root, like the preceding one, cannot be traced back to Arabic or Ethio-Semitic: nifir 'to be sweet', causative si-nafir 'to sweeten', adjective nafir 'sweet', masdar nafru:r 'sweetness'. They all apply to sweet food, or to any kind of pleasant food with a good taste.

Unlike in Kambaata, a Highland East-Cushitic language (Treis 2010: 239), there is no specific root for 'tasteless'. Beja uses either a negative noun phrase borrowed from Arabic: $b(i) l i: d ? a m<$ Arabic bila țaSam (lit. without taste) 'tasteless' (used as an adjective), or a negative verb phrase with a possession verb: $d$ Pam $k i=i$-bari 'tasteless' (lit. it does not have taste). The latter construction also means 'odorless', a case of cross-modal matching (or synaethesia), these matchings being common cross-linguistically for the sensory modalities (e.g. Viberg 1984; Boisson 1997: 5; Levinson \& Majid 2014: 414).

${ }^{11}$ jam 'water', a masculine plural noun, becomes feminine (a common way of forming diminutives) when designating a 'well' by contiguity extension. 


\subsection{Syntactic constructions}

The neuter gustatory verb $d$ Pam 'to taste of', although basically a sourceoriented experience verb, can be used in three different constructions: intransitively $(19,20)$, as expected, with or without an ablative/locative $3^{\text {rd }}$ person pronoun, which refers to the source or stimulus of the taste, but also transitively $(21,22)$ with an inanimate source as the subject.

Furthermore, the semantics of the utterance varies with the syntactic construction. When the ablative/locative pronoun is used, the type of taste is considered as an intrinsic gustatory property of the entity it refers to (19, 21). If this entity is lexically expressed, it is syntactically an object in the accusative case (21), as expected from a transitive construction. On the contrary, the entity is the subject if the gustatory property is not considered as intrinsic, and the source is the object of the verb (22) or if the noun is used in a copular expression instead of the verb (23).

(19) millak ho:j dPam-i:ni salt[SBJ] ABL.3 taste_of-IPFV.3SG.M

'It is intrinsically salty' (lit. salt tastes from/inside it)

(20) $s^{w} k^{w}$ ar diam-i:ni sugar[SBJ] taste_of-IPFV.3SG.M

'It tastes of sugar' (lit. sugar tastes) 
(21) $t e:=m l i$

mi:lak ho:j

DEF.PL.ACC=tearlPL salt[SBJ] ABL.3

dPam-i:ni

taste_of-IPFV.3SG.M

'Tears taste intrinsically of salt' (lit. salt tastes tears from/inside

it)

(22) ta:-mli

$$
\text { mi:lak diam-e:na }
$$

DEF.PL.NOM=tearlPL salt[OBJ] taste_of-IPFV.3SG.M

'The tears taste of salt'
(23)
ti=m?ari ala:w diam $=t=i$
DEF.F $[S B J]=$ food burnt $\quad$ taste=INDF.F $=C O P .3 S G$
'The food has a taste of burnt' (lit. is a burnt taste)

When a human experiencer is present in the utterance, two constructions are possible, either with the basic neuter verb diam, or with the masdar of the positive and negative verbs. With the neuter verb, the construction is intransitive, the experiencer is represented by a directional construction with the postposition $d h a: j$ (var. $d h$ before pronouns) and the subject is the source of the taste. 


$$
\begin{array}{ll}
\text { (24) } t i=m \text { Pari }:=t=i: b & s u k^{w} k^{w} a r=t \\
\text { DEF.F=food=INDF.F=LOC.SG } & \text { sugar=INDF.F } \\
d h-i & d \text { Pam-tini } \\
\text { DIR=POSS.1SG } & \text { taste_of-IPFV.3SG.F }
\end{array}
$$

'I taste sugar in the food' (lit. sugar tastes to me in the food)

With the masdars, the experiencer is the subject of the transitive verb miri 'to find', and the gustatory masdar is the object head of a genitive noun phrase.
(25) $s u k^{w} k^{w} a r=t-i$
nafru:r
sugar=INDF.F-GEN sweetness
$t i=m ?$ ari $i=t=i: b$
a-marri
DEF.F=food=INDF.F=LOC.SG 1 SG-find $\backslash I P F V$
'I taste sugar in the food' (lit. I find a sweetness of sugar in the food)
nifir 'be sweet', hamir 'be sour' and hami 'be bitter' are all intransitive stative verbs, and are all source-oriented.

\subsection{Metaphors}

Taste-based metaphors are much richer than olfactory-based ones, and involve all word categories. Twelve metaphors have been recorded so far. 
Depending on the context, $d$ ? $a m$, as a verb and a masdar, gives rise to metaphors in four semantic domains.

The first one refers to guessing. It makes use of the verb form in a construction with a benefactive auxiliary, where the source is the subject and the experiencer is expressed by an ablative/locative pronoun.

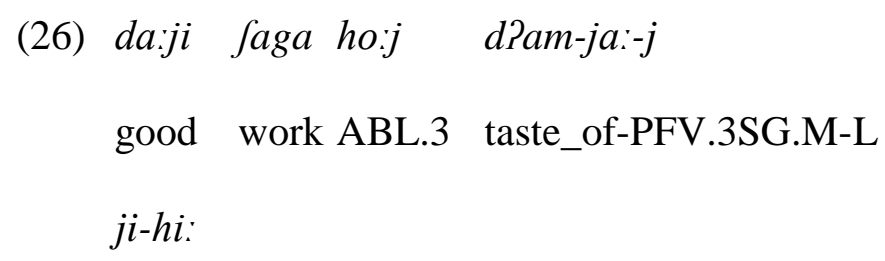

'He smelled a good bargain' (lit. a good work tasted from/inside him)

Positive and negative feelings and emotions can also be expressed with the noun form d?am as the object of the verb miri 'find' whose subject is the experiencer. The ablative/locative pronoun this time refers to the source. The precise type of feeling is determined by the context. The construction denotes suspicion in (27) (where d?am is the head of a genitive phrase), and pleasure in (28-29). The source of the feelings is represented by the ablative/locative pronoun in (27) and (28) and by a full lexeme with a locative postposition in (29).

\section{(27) farak-i dPam ho:j i-mri trap-GEN taste ABL.3 3SG.M-findIPFV}

'He smelled the trap' (lit. he found a taste of trap from/inside it) 
(28) ge: su:r $\quad$ sak-an=e:=na: $=t-i=k a$

DM before do-PFV.1SG=REL=thing=INDF.F-GEN=CMPR

tia dise:t diam ho:j a-mri

now slowly taste ABL.3 1SG-findIPFV

'Thus, in spite of what I did before, now, slowly, I really liked it' (lit. I found taste from/inside it)

(BEJ_MV_NARR_03_Camel_208-210)

(29)

$i=n e: w-a=e: b \quad$ diam miri-ti:t

DEF.M=insult-PL=LOC.PL taste find-CVB.SEQ

'After she was pleased with the insults...' (lit. she found taste in the insults) (BEJ_MV_NARR_25_Chief_074-075)

The last semantic domain of a taste-based metaphor is speech. The metaphor is constructed with the noun form $d$ ?am, which is the object of a possession verb. This metaphor is linked to the socio-discursive and stylistic rules of speech of the Beja society.

$$
\begin{array}{ll}
\text { (30) } i=\text { bhali=a:kna } & d i a m \\
\text { DEF.M=wordIPL=POSS.2PL.NOM } & \text { taste } \\
k i=i: \text {-bar }-i: n &
\end{array}
$$

NEG.IPFV=3-have $\backslash A O R-P L$

'Your words are improper' (lit. your words have no taste)

(Roper 1928: 171) = your words do not respect the Beja sociodiscursive and stylistic rules 
With the causative derived verb form $d$ ?am-s, another metaphor of feeling is built, namely a metaphor of suffering (physical or psychological) which includes a synaethesia from the touch modality: The object of the verb consists of the dummy noun $n a$ 'thing' and the temperature adjective nab? $a$ 'hot'. ${ }^{12}$ The experiencer is the subject.

$$
\begin{aligned}
& \text { (31) nab?a na diam-s-ja } \\
& \text { hot thing taste-CAUS-PFV.3SG.M } \\
& \text { 'He suffered' (lit. 'he tasted a hot thing') }
\end{aligned}
$$

The gustatory adjectives can be used to characterize voice types, a case of synaethesia to the hearing domain, and characters or behaviors, bad or good. Even though hamir 'sour' is experienced as pleasant in the sensory modality domain, it gives rise to a negative metaphor: hamr-a his (lit. sour voice) is always felt negatively and refers to a too deep voice. It is said of a male voice, also when not perfectly in tune. hami his (lit. bitter voice) is also felt negatively and simply refers to the unpleasant voice of a singer. nafir 'sweet' provides a pleasant judgement as in (32), where his 'voice' is in the genitive case (the same syntactic construction applies to the other two adjectives), in an attributive construction with a copula.

${ }^{12}$ Note that in many other languages (see e.g. the articles in KoptjevskajaTamm 2017), hot temperature is associated with pain. 
(32) nafir his- $i:=b=i$

sweet voice-GEN=INDF.M=COP.3SG

'He has a nice voice' (lit. he is a of sweet voice)

Applied to bhali 'words', the adjective nafir 'sweet', as in nafir bhali 'sweet words', implies that the speaker's formulation and choice of words perfectly respects the Beja socio-discursive and stylistic rules (cp. ex. 30).

Only nafir and hami are used to qualify positively and negatively, respectively, someone's character or the behavior. The head noun is also in the genitive, in an attributive construction with a copula.

(33) hami $d a b-i:=b=i$

bitter character-GEN=INDF.M=COP.3SG

'He has a bad character' (lit. he is of bitter character)

(34) nafir $\quad d a b-i:=b=i$

sweet character-GEN=INDF.M=COP.3SG

'He is easy-going' (lit. he is a of sweet character)

\section{Touch}

\subsection{Organization of the lexicon}


The tactile sense is lexically the less represented. It is expressed by four roots and thirteen items (23.20\% of the lexicon of the lower senses): two roots in the verb (seven items) and noun (two items) categories, and two other roots (two items) in the adjective category. They are presented below in Table 3, grouping together the tokens belonging to the same root, regardless of intensity and hedonic polarity which are irrelevant for this sensory modality at the root level.

Table 3. The tactile lexicon of Beja

\begin{tabular}{|l|l|l|}
\hline Verb & Noun & Adjective \\
\hline $\begin{array}{l}\text { tha 'touch' } \\
\text { tha-s } \\
\text { tha-m } \\
\text { tha-s-am } \\
\text { tha tha }\end{array}$ & tha-ti 'touching' & \\
\hline $\begin{array}{l}\text { fi:f'run one's hand on s.th' } \\
\text { fa fi:f }\end{array}$ & & \\
\hline$n ? a k^{w}$ 'be tender' & fa fi:f-ti 'groping' & \\
\hline & & $n ? a k^{w}$ 'tender' \\
\hline
\end{tabular}

The basic transitive verb is tha 'to touch', masdar tha-ti. It has four derived forms: causative tha-s, middle tha- $m$, reciprocal-sociative tha-s-am, pluractional tha tha 'to frisk, palpate'. ${ }^{13}$

The transitive verb $\int i: \int$ is specifically 'to run one's hand on s.th'. It is translated as 'fühlen' ('to feel') by Reinisch. Roper only provides the

${ }^{13}$ Strik Lievers (2007: 178) is right in remarking that 'touch' verbs "do not describe a perception, but an action causing a perception". 
pluractional form $\int a \sim f i: \int^{\prime}$ to grope'. It has a masdar form, $\int a \sim f i: f-t i$ 'groping, passing the hand repetitively on something to caress, examine a content...' Two adjectives are typically related to the tactile domain: lamsa 'smooth' (which is a borrowing with a metathesis from the Arabic adjective Pamlas 'smooth', and has no corresponding verb or noun form), and $n ? a k^{w}$ 'tender'. The antonym of the former is formed by a negative verb phrase lams $a:=b$ $k i-i k i$ 'rough, rugged, coarse' (lit. it is not smooth). The second adjective can also be used as a stative verb: $n$ ?ak 'to be tender'.

\subsection{Syntactic constructions}

Contrary to olfaction and taste, both tactile verbs are transitive and experiencer-oriented.
$i=j a f=0$ :
tha-ta

DEF.M=mouth=POSS.3SG.ACC touch-PFV.3SG.F

'She touched her mouth' (BEJ_MV_NARR_12_Witch_060)

(36)

$w=$ Pargin $\quad$ in $=$ da:ji $i=b \quad$ ti-kte:na

DEF.M=sheep $\quad$ DEF.M=good=REL.M 2SG.M-know $\backslash$ IPFV

fi:f-ti:=ho:b

rub_one's_hand_on-AOR.2SG.M=when

'Do you recognize the good sheep when you rub your hand on it?' 


\subsection{Metaphors}

Although less rich lexically than the two other senses, touch nevertheless is used in seven metaphorical expressions, more than olfaction, but less than taste.

The verb tha 'to touch' is used to express two psychological states, comfort and bewitchment. For the former, tha is associated to a body part, gin?i 'heart' and an ablative/locative construction.

(37) $i=\sin P=o: k$

DEF.M=heart=POSS.2SG.ACC

$w=h e: r=i: \quad$ tha- $a$

DEF.SG.M=good=ABL.SG touch-IMP.SG.M

'Feel at ease!' (lit. touch your heart from/inside the good)

(BEJ_MV_NARR_08_Drunkard_123)

For bewitchment, two constructions are possible, one with the basic transitive verb, where the agent of the bewitchment is mentioned as the subject and the experiencer as the object (38), or with the derived middle form with no agent overtly expressed and where the experiencer is the subject (39). 


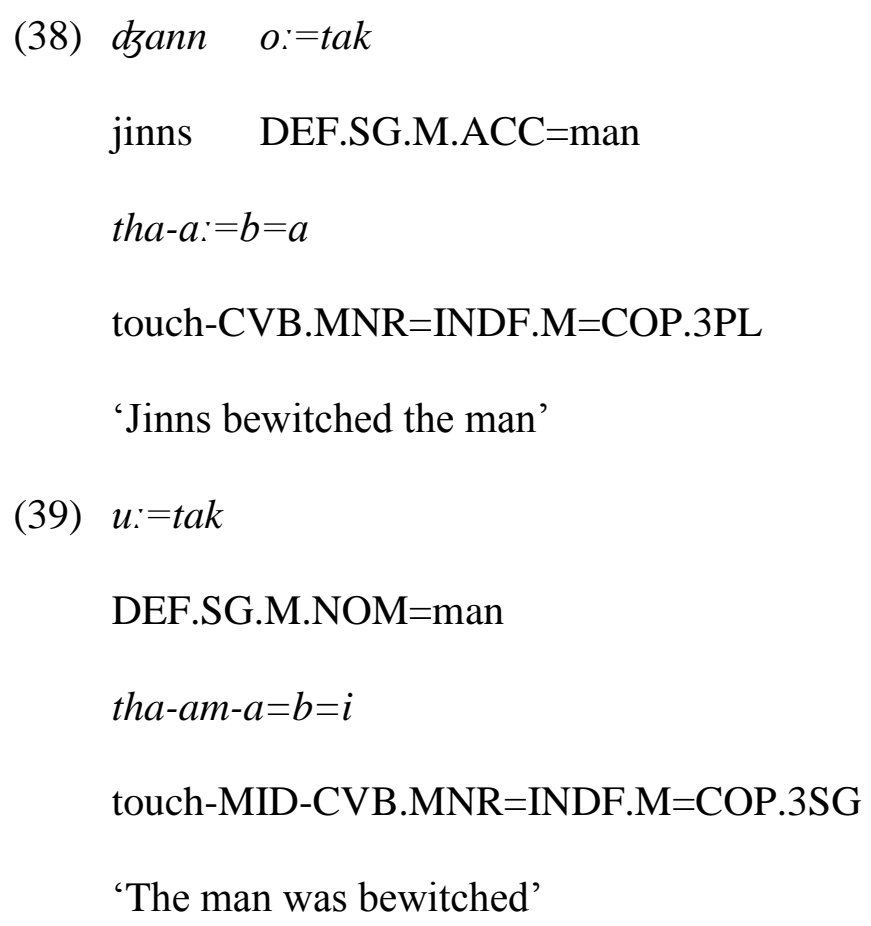

tha is also part of an idiomatic compound with the verb hagil 'to miss, to lack', in a nominalized construction with the manner converb form. It expresses the irregularity of an activity as in (40).

(40) $t i=m P a r i=t=u$ :

DEF.F=food=INDF.F=POSS.3SG.NOM

hagil-a-tha- $a=t$

miss-CVB.MNR-touch-CVB.MNR=INDF.F

ti-kati

3SG.F-becomelIPFV

'He is given food irregularly' (lit. his food becomes a missingtouching) (BEJ_MV_NARR_26_Orphan_018-021) 
tha can also express physical pain, more precisely a physical wound.

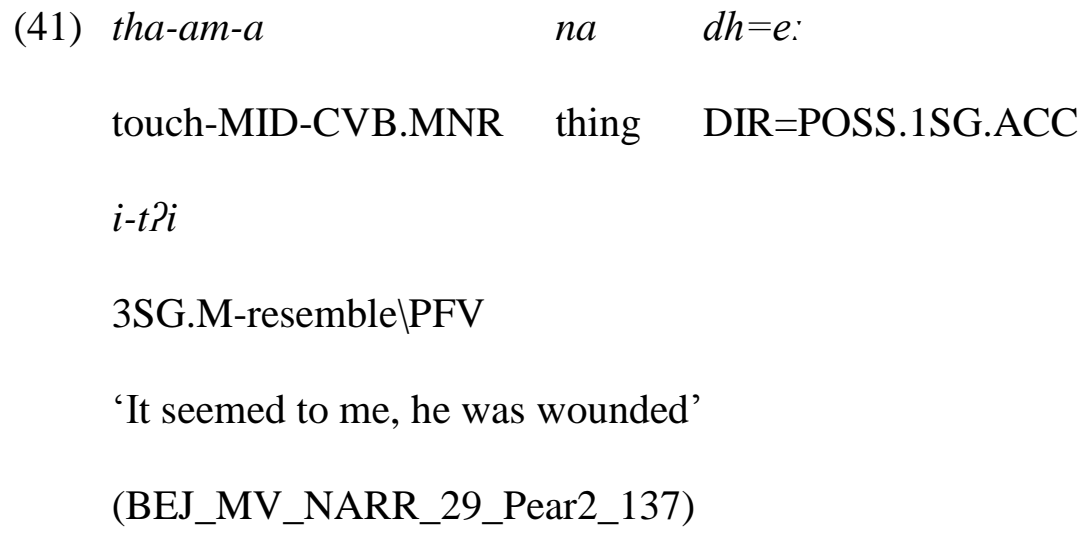

Lastly, tha can also mean 'to receive' in two contexts: money (42) (as in French) and commercial transactions (43-44). In the latter case, the commercial transaction itself is not mentioned, but the two parties are, as subject (lexically (43) and/or as a subject index (44) on the verb) and direct object.

(42) $t i=$ ma:hija:j $\quad$ tha $-a=b=i$

DEF.F=salary touch-CVB.MNR=INDF.M=COP.3SG

'He had received his salary'

(43)
$u:=\operatorname{tak}$
$i=d i k^{w} a n-i$
kina

DEF.SG.M.NOM=man

DEF.M=shop-GEN owner

tha- $a=b=i$

touch-CVB.MNR=INDF.M=COP.3SG

'The man had received something (money or object) from the shopkeeper' 
(44) $0:=$ firim

tha $a=t=u: j$

DEF.SG.M.ACC=baker touch-CVB.MNR=INDF.M=COP.2SG

'Have you received something from the baker?'

The tactile adjective and verb, $n ? a k^{w}$ '(to be) tender', also give rise to metaphors. They are used to describe characters and cognitive properties of beings in a more precise way than gustatory adjectives and feelings. 'Intelligence', $n ? a k^{w} f a m$, is composed of the tactile adjective and the masdar of the verb 'to understand', lit. 'tender understanding'. Its antonym is not based on a tactile adjective: akra fam 'stupidity', lit. 'strong understanding'. The combination of the stative verb form $n ? a k^{w}$ with a body part, namely mana 'bowel', as its subject, expresses pity and compassion. The experiencer of this feeling is only deductible from the context.
$i=$ mana
dha:j $\quad i-n ? a k^{w}-n=h o: b$

DEF.M=bowels DIR 3-become_soft $\ P F V-P L=w h e n$

'When I pitied him...' (lit. When the bowels became soft

towards him) (BEJ_MV_NARR_15_Leopard_080)

The expression for a tough character, ruthless, pitiless, akra mana 'strong bowels', is not based on the gustatory lexicon (but the body part remains).

\section{Conclusion}


Compared with other non-Indo-European languages such us Amis (Formosan, Austronesian) (Lee 2015), Aslian languages (Austronesian) (Burenhult \& Majid 2011), Totonac (Mixe-Zoque, Mexico) (Aschmann 1946), Hawaiian (Polynesian, Austronesian) (Boisson 1995: 9), Jahai (MonKhmer) (Majid \& Burenhult 2014), or the African languages mentioned in Section 1, the lexicon of the lower senses is not very elaborate in Beja. Still some interesting results emerged from our preliminary investigation.

The organization of the lexicon across word categories shows a prevalence of the verb category over nouns and adjectives (and manner converbs), and a more varied lexicon for the olfactory modality than for gustatory and the tactile ones.

In the domain of repellent smells, noteworthy is the existence of a specialized mono-lexemic root for a fermented smell, recorded only in one (unspecified) language in Boisson's (1997: 41) sample of 60 languages. Still, Beja is one more illustration of a general tendency across languages (Buck 1949; Boisson 1997: 38) to have a terminological prevalence (in terms of different roots and meanings) of repellent smells over pleasant ones.

The connection between weather and temperature terminology and part of the olfactory lexicon, be it the polysemy with 'wind', 'weather', 'breeze', or the use of the temperature qualia 'cold', is also remarkable. Whether the weather polysemy is due to language contact with Sudanese 
Arabic or not is difficult to assert. To the best of our knowledge, it is not attested in East-Cushitic or Central Cushitic, the closest relatives of Beja within the Cushitic branch, but this pattern also exists in unrelated language, e.g. in other African languages such as Dendi (Songhay, Nilo-Saharan), Bwamu (Gur, Niger-Congo), Sereer and Peul (Atlantic, Niger-Congo) (see Segerer \& Flavier 2011-2018). Moreover, 'wind' is considered as the source of olfactory words in a few Indo-European languages (Buck 1949 [1988]: 1024). For lack of comparative data with other Cushitic languages, it is impossible to assess which of the two meanings is the source of a possible semantic evolution in Beja at the origin of the actual polysemy. On the other hand, the link between 'wind' and 'smell' in Beja bears no trace of a possible ancient meaning 'type of odor blown by the wind' lexicalized in unrelated languages such as Hawaiian (Boisson 1995: 39).

For the gustatory domain, one can remark that most of the roots are borrowings from the contact language, Sudanese Arabic, which probably mirrors the fact that the traditional diet of the Beja people is not very diverse. Nevertheless, it is interesting to note that Beja is one of these languages where evaluative taste words conflate (excess of) bitterness and (excess of) salt (see Myers 1904; Majid and Levinson 2008, for the various semantic partitioning and groupings of taste words across languages). Krifka (2010: 239), basing his remark on English and German data only, postulates a general positive hedonic implicature for general words denoting the sense of taste. If this would need to be confirmed by empirical data from 
other languages, at least Beja shows the same partitioning as English and German.

As far as the lexicon is concerned, the tactile domain can be considered as poor in Beja.

Regarding the syntactic constructions, we can recall that verb constructions are predominantly source-oriented for the olfactory and gustatory domains, while the tactile one is active.

Since Sweetser's (1990) study of the semantic changes in the domain of English senses where she established the metaphorical mappings of the lower senses as going from TASTE to LIKES and DISLIKES, TOUCH to FEELINGS, and SMELL to 'DISLIKEABLE' FEELINGS, further studies (e.g. Ibarretxe-Antuñano 1999 for English, Spanish and Basque) have shown other metaphorical extensions that, even in English, go beyond these semantic targets.

In Beja, olfaction develops metaphors for a very restricted number of both positive and negative feelings and emotions, as in the three languages mentioned by Ibarretxe-Antuñano.

In spite of a rather poor lexicon, and a not very varied diet, it is the gustatory sense that is most often recruited for metaphorical extensions, including for domains where olfaction is recruited in other languages, such as guessing or suspicion (see e.g. Viberg 1984: 158, based on Ullmann 1957: 266ff). Similarly, the temperature adjective for 'hot' is recruited for a taste-based metaphor where other languages apply it to olfaction words 
(Wnuk et al. 2017). It should be noted that the 'cold' adjective applies to olfaction, without a metaphorical extension of the smell word itself.

As for the tactile domain, which is lexically even poorer than taste, metaphorical extensions show quite a large variety, which includes the semantic fields of cognition, psychological states and feelings, physical pain, money or goods reception, irregular activities. Some of them are known in unrelated languages such as French for the physical pain and the reception of money or goods, or Lussusu (also known as Lussese), a Bantu language, for bewitchment (Thanassoula 2012: 318). Others are more unexpected from a western perspective such as 'irregularity' expressed by a transparent compound involving success or failure of the touch activity, 'intelligence' which combines tenderness with an Arabic borrowing, fam 'understanding', or 'pity' which associates an internal body part and softness.

Viberg (1984: 159) recalls Ullmann's (1957) study of transfers from one perception domain to another in a corpus of $19^{\text {th }}$ century poetry in which, on the basis of frequency, he proposed the following hierarchy:

$$
\text { touch }>\text { hear }>\text { taste }>\text { scent }>\text { sound }>\text { sight }
$$

Even though we could not conduct a frequency analysis, it is interesting to note that as far as the number of synaethesias is concerned, Beja does not confirm this hierarchy, with three metaphorical transfers to another sensory modality for taste, and none for touch and smell. 


\title{
Acknowledgments
}

Our thanks are due to the Beja speakers who provided the corpus examples, Ahmed Abdallah Mohamed-Tahir, his mother and siblings, the CNRS research unit Llacan and the Labex EFL who funded this research and the Paris stay of the second author, our colleague Guillaume Segerer from Llacan who attracted our attention to the data of Setswana and Lomongo, and the two anonymous reviewers for their constructive comments and suggestions.

\author{
Abbreviations \\ 1/2/3 1st/2nd/3rd person; ABL ablative/locative; ACC accusative; AOR \\ aorist; AUG augmentative; CAUS causative; CMPR comparative; COORD \\ coordination; COP copula; CVB converb; DEF definite; DIR directional; \\ DM discourse marker; F feminine; GEN genitive; IMP imperative; INDF \\ indefinite; IPFV imperfective; LOC locative; M masculine; MID middle; \\ MNR manner; N.AC action noun, masdar; NEG negation; NOM \\ nominative; OBJ object (pronoun); OPT optative; PFV perfective; PL \\ plural; PLAC pluractional; POSS possessive; REL relator; SBJ subject; \\ SEQ sequential; SG singular.
}




\section{References}

Aschmann, Herman. 1946. Totonac categories of smell. Tlalocan 2: 187189.

'Awn Al-Sharif Qasim. 2002. Qāmūs al-lahja al-'arabiyya fì l-Sūdān.

[Dictionary of the Arabic variety of Sudan]. Khartoum: Al-Dar alSūdānijja lil-Kitab.

Blench, Roger \& Selbut R. Longtau. 1995. Tarok ophresiology: An investigation into the Tarok terminology of odours. In Issues in African Languages and Linguistics: Essays in Honour of Kay Williamson [Special Issue of the Nigerian Language Studies], 'Nọlue Emenanjọ \& Ozo-mekuri Ndimele (eds), 340-344. Aba: National Institute for Nigerian Languages.

Boisson, Claude. 1997. La dénomination des odeurs: variations et régularités linguistiques. Intellectica 24(1): 29-49.

Buck, Carl Darling. 1988 (1949). A Dictionary of Selected Synonyms in the Principal Indo-European Languages: A Contribution to the History of Ideas. Chicago and London: University of Chicago Press.

Burenhult, Niclas \& Asifa Majid. 2011. Olfaction in Aslian ideology and language. The Senses \& Society 6(1): 19-29. 
Creissels, Denis \& Andy M. Chebanne. 2000. Dictionnaire françaissetswana, setswana-français. Mogoditshane (Botswana) \& Gaborone: Tasalls Publishing \& Books.

Dingemanse, Mark. 2011. The meaning and use of ideophones in Siwu. PhD dissertation. Radboud University. Retrieved from http://thesis.ideophone.org/.

Dingemanse, Mark \& Asifa Majid. 2012. The semantic structure of sensory vocabulary in an African language. In Proceedings of the 34th Annual Meeting of the Cognitive Science Society (CogSci 2012), Inoue Miyako, David Peebles \& Richard P. Cooper (eds), 300-305. Austin, TX: Cognitive Science Society.

Hulstaert, Gustaaf. 1957. Dictionnaire lomongo-français. Tervuren : Musée Royal du Congo Belge (MRCB).

Ibarretxe-Antuñano, Iraide. 1999. Metaphorical mappings in the sense of smell. In Metaphor in Cognitive Linguistics [Current Issues in Linguistic Theory 175], Raymond W. Gibbs \& Gerard J. Steen (eds), 29-45. Amsterdam: John Benjamins.

Juvonen, Païvi \& Ahti Nikunlassi. 2015. Temperature adjectives in Finnish. In The Linguistics of Temperature [Typological Studies in Language 107], Maria Koptjevskaja-Tamm (ed), 491-536. Amsterdam: John Benjamins.

Koptjevskaja-Tamm, Maria (ed). 2015. The Linguistics of Temperature [Typological Studies in Language 107]. Amsterdam: John Benjamins. 
Krifka, Manfred. 2010. A note on an asymmetry in the hedonic implicatures of olfactory and gustatory terms. In Between the Regular and the Particular in Speech and Language, Susanne Fuchs, Phil Hoole, Christine Mooshammer \& Marzena Żygis (eds), 235-245. Frankfurt am Main: Peter Lang.

Kryvenko, Anna. 2015. In the warmth of the Ukrainian temperature domain. In The Linguistics of Temperature [Typological Studies in Language 107], Maria Koptjevskaja-Tamm (ed), 300-332. Amsterdam: John Benjamins.

Lee, Amy Pei-Jung. 2015. Lexical categories and conceptualization of olfaction in Amis. Language and Cognition 7(3): 321-350.

Levinson, Stephen C. \& Asifa Majid. 2014. Differential ineffability and the senses. Mind \& Language 29(4): 407-427.

Majid, Asifa \& Stephen C. Levinson. 2008. Language does provide support for basic tastes [Commentary on A study of the science of taste: On the origins and influence of the core ideas by Robert P. Erickson]. Behavioral and Brain Sciences 31(1): 86-87. doi:10.1017/S0140525X08003476.

Majid, Asifa, Gunter Senft \& Stephen C. Levinson. 2007. The language of olfaction. In Field Manual 10, Asifa Majid (ed), 36-41. Nijmegen: Max Planck Institute for Psycholinguistics.

Mattiola, Simone. 2017. The conceptual space of pluractional constructions. Lingue et Lingguagio 16(1): 119-146. 
Myers, Charles S. 1904. The taste-names of primitive peoples. British Journal of Psychology 1(2): 117-126.

Rasulić, Katarina. 2015. What's hot and what's not hot in English and Serbian. In The Linguistics of Temperature [Typological Studies in Language 107], Maria Koptjevskaja-Tamm (ed), 300-332. Amsterdam: John Benjamins.

Reinisch, Leo. 1895. Wörterbuch der Bedawiye-Sprache. Wien: Kaiserische Akademie der Wissenschaften.

Roper, E. M. 1928. "TuBedawiع". An Elementary Handbookfor the Use of Sudan Government Officials. Herford, Herts: Stephen Austin \& Sons. Segerer, Guillaume \& Sébastien Flavier. 2011-2018. RefLex: Reference Lexicon of Africa, Version 1.1. Paris, Lyon. http://reflex.cnrs.fr/. Accessed 2018/01/04.

Siahaan, Poppy. 2015. Why is it not cool? Temperature terms in Indonesian. In The Linguistics of Temperature [Typological Studies in Language 107], Maria Koptjevskaja-Tamm (ed), 666-699. Amsterdam: John Benjamins.

Storch, Anne. 2004. Haptische, visuelle und olfaktorische Sprachen: Westnilotische Wahrnehmungen. Afrikanistik-Aegyptologie-online. <https://www.afrikanistik-aegyptologie-online.de/archiv/2004/45> (01 October 2017) 
Strik Lievers, Francesca. 2007. Italian Perception Verbs. A Corpus-based Study. In Language Resources and Linguistic Theory, Andrea Sansò (ed.), 167-179. Milano: Franco Angeli.

Sweetser, Eve. 1990. From Etymology to Pragmatics [Cambridge Studies in Linguistics 54]. Cambridge: Cambridge University Press.

Thanassoula, Marilena. 2012. The perception verbs in Lussese (Bantu J10): A matter of experience. In Language Documentation and Description, vol 10: special issue on Humanities of the Lesser-known: New Directions in the Description, Documentation and Typology of Endangered Languages and Musics, Jan-Olof Svantesson, Niclas Burenhult, Arthur Holmer, Anastasia Karlsson \& Håkan Lundström (eds.), 307-328. London: SOAS.

Treis, Yvonne. 2010. Perception verbs and taste adjectives in Kambaata and beyond. Sprache und Geschichte in Afrika 21: 313-346.

Ullmann, Stephen. 1957. Principles of Semantics. Glasgow: Jackson. van Beek, Walter E. A. 1992. The dirty smith: Smell as a social frontier among the Kapsiki / Higi of north Cameroon and north-eastern Nigeria. Africa 62(1): 38-58.

Vanhove, Martine. 2014. The Beja Corpus. In The CorpAfroAs Corpus of Spoken AfroAsiatic, Mettouchi, Amina \& Christian Chanard (eds). <http://dx. doi.org/10.1075/scl.68.website> (01 October 2017)

Vanhove, Martine. 2017. Le bedja. Leuven, Paris: Peeters. 
Vanhove, Martine. 2018. The Beja corpus. In The CorTypo Corpus Amina Mettouchi \& Christian Chanard (eds) <http://cortypo.humanum.fr/index.html> (01 October 2017)

Viberg, Åke. 1984. The verbs of perception: A typological study. Linguistics 21(1): 123-162.

Wnuk, Ewelina, Josje M. de Valk, John L. A. Huisman \& Asifa Majid. 2017. Hot and cold smells: Odor-temperature associations across cultures. Frontiers in Psychology 8(1373): 1-7. doi: 10.3389/fpsyg.2017.01373. 